\title{
Thoughts on Constructing Long-acting Mechanism of Mass-line Educational Practice in Higher Vocational Colleges
}

\author{
Ouyang Dongmei ${ }^{1}$, Hongbao $\mathrm{Luo}^{1}$, Yiming Wang ${ }^{1}$ \\ ${ }^{1}$ Jiangxi Modern Polytechnic College, Nanchang, 330095, China
}

Keywords: Significance; Connotation; Requirement

\begin{abstract}
Educational practice is terminable, while enhancing work style construction is dateless. As the witness of mass-line educational practice of CPC, I have many feelings. How to continue to take mass line and cultivate high-quality technical talents? This cannot be separated from construction of long-acting mechanism. This paper based on actual conditions of higher vocational colleges discusses significance, basic requirements and connotation of constructing long-acting mechanism mass-line educational practice of CPC and offers theoretical foundation for studying specific countermeasures to construct long-acting mechanism.
\end{abstract}

\section{Introduction}

On October 8, 2014, summary conference of CPC mass-line educational practical activity was convened in Beijing. General Secretary Mr. Xu gave an important speech, fully affirmed great achievements of CPC mass-line educational practical activity, profoundly summarized successful experiences of educational practice, and overall deployed ruling the Party strictly under the new situation. His speed has strong ideology, pertinence and guidance. Deep implementation of CPC mass-line educational practical activity is a significant strategic decision made by the $18^{\text {th }}$ National Congress of the Communist Party of China and also an important move of CPC to stick to that the Party exercises self-discipline and is strict with its members under the new situation. The activity plays a positive role in further improving school spirit, style of study and style of work of hiver vocational colleges, improving talent training quality, boosting management level of Party members, improving the relationship between cadres and the masses and solving actual problems of teachers and students. However, relative to universities, higher vocational colleges pay attention to skills, ignore theories and have low education background. This gives rise to great challenges to this activity. In some higher vocational colleges, theoretical basis of CPC is weak. Thus, cognitive fuzziness is caused. Some fail to pay sufficient attention to the activity. Improper attitude, slow action, formalism and bureaucratism still exist. Besides, some thoughts and practices appear: "there is no formalism, bureaucracy, hedonism and extravagance, so it is unnecessary study"; "after the activity is finished, there is nothing to do"; unwilling to go deep among teachers; copy wrong thought ad practice. Thus, higher vocational colleges shall serve teachers and students heart and soul, and achieve the ambitious goal of running satisfying vocational education. It is required to summarize activity experience, perfect measures, consolidate results, establish and perfect long-acting mechanism and transform new achievements of CPC mass-line educational practical activity to new practice of connotation construction of higher vocational colleges.

\section{Significance of constructing long-acting mechanism of CPC mass-line educational practical activity in higher vocational colleges}

1). Constructing long-acting mechanism of CPC mass-line educational practical activity in higher vocational colleges is the need of higher vocational colleges to cultivate and practice socialist core values.

Since y the $18^{\text {th }}$ National Congress of the Communist Party of China, the Central Committee of the Communist Party of China has paid high attention to cultivating and practicing socialist core values 
and explicitly putting forward "richness and strength, democracy, civilization, harmony, freedom, equality, justice, rule by law, patriotism, dedication, integrity and friendliness”.

The core value needs the most extensive approval. To cultivate and practice socialist core values, leaders and teaching staff in higher vocational colleges should take the lead. Only when leaders and teaching staff change style of work, tell the truth, handle concrete affairs, go deep into grass roots, know needs of the masses, solve students' actual problems, abandon selfish idea, establish the model of loving teachers and students and work diligently can vast masses better approve socialist core values.

2). Constructing long-acting mechanism of CPC mass-line educational practical activity in higher vocational colleges is the need of higher vocational colleges to intensify connotation construction.

The report of the $18^{\text {th }}$ National Congress of the Communist Party of China proposes the goal of running satisfying education. This profoundly reveals intimate connection between educational development and needs of the masses. Education quality should be subject to "people's satisfaction". Vocational education as an important constituent part of national education and human resource cultivation undertakes the arduous task of providing talent guarantee for the objective of "two hundred years" and China dream of great rejuvenation. Through continuous exploration and practice, higher vocational colleges have gained outstanding achievements in talent cultivation and social service. But, there is still a large gap with expectations of the masses, social economic development and talent demand for transition.

To narrow the gap, complete the task and intensify connotation construction, higher vocational colleges cannot be separated from the support of masses. Connotation construction of higher vocational colleges can be promoted only through concentrating people's wisdom, depending in the people and creating united political atmosphere.

3. Constructing long-acting mechanism of CPC mass-line educational practical activity in higher vocational colleges is the need of continuously improving quality of party members in higher vocational colleges.

Higher vocational colleges conduct learning according to general requirements of "looking into the mirror to make the clothes properly, washing and treating illness" and in combination of their actual conditions and let Party members receive theoretical baptism of CPC, systematically learn constitutions and disciplines of CPC and deepen cognition of all Party members for Marxian mass viewpoint and mass theory of CPC.

However, higher vocational colleges are not vacuum zone. Some unhealthy ways and customs in society still erode this team. Besides, the theoretical basis is weak and work style construction is not solid enough. To keep good work style and continuously improve quality level of Party members, effective learning atmosphere such as mass-line educational practical activity is needed. Without such atmosphere, the improvement of quality level of Party members lacks powerful operation guarantee.

\section{Connotation of constructing long-acting mechanism of CPC mass-line educational practical activity in higher vocational colleges}

Connotation research is the key to deeply discussing constructing long-acting mechanism of CPC mass-line educational practical activity. To understand this problem, we analyze it from three perspectives: 1) definition of "long-acting mechanism"; 2) what is long-acting mechanism of CPC mass-line educational practical activity? 3) Mass competition of higher vocational colleges.

Long-acting mechanism is a phrase consisting of an adjective "long-acting" and a noun "mechanism". "Long-acting” means normalcy, long tem and efficiency. "Mechanism” is a kind of running way and an integral whole where each sub-system interacts and interrelates. Long-acting mechanism of CPC mass-line educational practical activity means to ensure normalization and efficiency of CPC mass-line educational practical activity in quite a long time and keep an integral whole of CPC and people. To analyze connotation of constructing long-acting mechanism of CPC mass-line educational practical activity, mass competition of higher vocational colleges must be 
distinguished. A higher vocational college is a collectivity composed of students, teaching faculty and staff. Education is the root. Students and teachers are the mass subjects of a higher vocational college and also fundamental objects of mass-line educational practical activity. Therefore, constructing long-acting mechanism of CPC mass-line educational practical activity should regard students and teachers as the core to construct institutional organism keeping eternal connection with teachers and students. The organism should cover responsibility management implementation mechanism, Party member education and learning mechanism, Party member supervision and restriction mechanism, Party member-mass connection mechanism, Party democracy mechanism as well as reward and punishment assessment mechanism etc.

\section{Basic requirements of constructing long-acting mechanism of CPC mass-line educational practical activity in higher vocational colleges}

1). To explore construction of long-acting mechanism of CPC mass-line educational practical activity in higher vocational colleges, it is required to put teachers and students first. Making masses satisfied is the value orientation and fundamental of all work of CPC. Teachers and students are the core subjects of mass-line educational practical activity in higher vocational colleges. Mass line must open the door, depend on teachers and students and actively receive supervision and judgment of teachers and students. During construction of long-acting mechanism, the interest of teachers and students 9especially students' interest) shall be put in the first place, and the ides of serving teachers and students should be introduced to construct the channels with smooth communication, smooth problem feedback and effective supervision, explore more good methods and systems to solve actual problems and make a platform for students.

2). To explore construction of long-acting mechanism of CPC mass-line educational practical activity in higher vocational colleges, it is required to be realistic and pragmatic. To be realistic and pragmatic is a basic view of historical materialism, also core content and fine tradition of CPC's ideological line. It is still political character every CCP member should own. In a bid to construct long-acting mechanism of mass-line educational practical activity, it is required to carry forward the spirit of looking for the truth and being practical in higher vocational colleges. Without the principle of being realistic and pragmatic, work style construction will naturally become empty talk and superficial. The achievements of practical education cannot keep and successful experience cannot be really rooted.

3). To explore construction of long-acting mechanism of CPC mass-line educational practical activity in higher vocational colleges, it is required to stick to unification of scientificity, systematicness, feasibility and innovation. Institutional construction is the foundation of mechanism construction. Construction of long-acting mechanism of CPC mass-line educational practical activity in higher vocational colleges is not equal to single institutional construction, but cannot be separated from scientific and effective institutional guarantee. To construct long-acting mechanism, it is required to firmly seize rules of vocational education and advanced experience of higher vocational colleges in educational practice, summarize researches, generalize long-term and universal traits, systematize and standardize them to form an organic and uniform long-acting mechanism chain which complied with characteristics of higher vocational colleges.

4). To explore construction of long-acting mechanism of CPC mass-line educational practical activity in higher vocational colleges, it is required to firmly implement the policy that the Party exercises self-discipline and is strict with its members. Being strict with Party members is a topic in need of continuous exploration and practice. The higher vocational college is one of important gathering places of Party members. Construction of long-acting mechanism must firmly implement the policy that the Party exercises self-discipline and is strict with its members, further carry out the responsibility of being strict with Party members, grasp the rules of being strict with Party members, specify Party disciplines, stock to unifying Party building through thought and system, management cadres strictly, further make political life of CPC serious, continuously improve work style construction and give play to supervision function of the masses. Only when self-discipline 
awareness of Party members and cadres improve can long-acting mechanism be transformed to actual effects.

In one word, constructing long-acting mechanism of CPC mass-line educational practical activity in higher vocational colleges is a system project. We should own the thought of protracted war. Shallow thoughts cannot solve concrete problems in practice. Long-acting mechanism construction still needs further exploration and practice.

\section{Acknowledgments}

This paper is one of achievements of 2014 planning program of Jiangxi colleges about studying Party building "Study on Construing Long-acting Mechanism of CPC Mass-line Educational Practice in Higher Vocational Colleges”; program No.: JXGXDJKT.YB-201470.

\section{References}

[1] Baidu Encyclopedia. Mechanism [EB/OL].http://baike.baidu.com/view/79349.htm.

[2] Xinhuanet. Xi Jinping: Speech on summary conference of CPC mass-line educational practical activity[EB/OL]. http://news.xinhuanet.com/politics/2014-10/08/c_1112740663.htm.

[3] Zhang Ze, Jiang Yun'er, Thoughts of countermeasures for higher vocational colleges to construct long-acting mechanism of CPC mass-line educational practical activity. Journal of Jincheng Institute of Technology, 2014 (7).

[4] Research group of Fujian Provincial Party School. Survey and thought of constructing long-acting mechanism to keep advancement of Party members. Journal of Fujian Provincial Committee Party School of CPC, 2005 (12).

[5] Luo Qingzhen, Study on implementing CPC mass-line educational practical activity in higher vocational colleges. Education Science \& Culture Magazine, 2013 (12).

[6] Tian Xinming, Mass line: from Mao Zedong to the 18th National Congress of the Communist Party of China. Journal of Ideological \& Theoretical Education, 2013 (7).

[7] Xu Yaotong, Cognition about formation and development of CPC mass line. Theory Reserch, 2013 (7).

[8] Feng Ping, Characteristics and innovation approaches of Party building in higher vocational colleges. Communist Party Construction and Ideological Education of School, 2010 (8).

[9] Hu Yong, Exploration and analysis of Party building in higher vocational colleges. Forum on Contemporary Education, 2007 (7). 